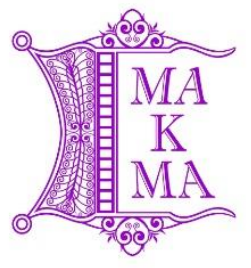

Majalah Kesehatan Masyarakat Aceh (MaKMA)

http://ojs.serambimekkah.ac.id/index.php/makma

\title{
ANALISIS INDEKS KELUARGA SEHAT DI GAMPONG LINTASAN HAULING PT MIFA BERSAUDARA KABUPATEN ACEH BARAT
}

\section{Teungku Nih Farisni, Fitrah Reynaldi}

Fakultas Kesehatan Masyarakat Universitas Teuku Umar. Aceh, Indonesia.

${ }^{\square}$ Alamat Korespondensi: Fakultas Kesehatan Masyarakat Universitas Teuku Umar, Meulaboh, Email: teungkunihfarisni@utu.ac.id, fitrahreynaldi@utu.ac.id

\begin{abstract}
ABSTRAK
Program Indonesia sehat sebagai upaya meningkatkan kualita hidup manusia Indonesia yang diwujudkan dalam rencana strategis kementrian kesehatan 2015-2019. PT Mifa Bersaudara merupakan perusahaan bersaudara yang mulai beroperasi pada tahun 2012. Tujuan penelitian ini adalah ingin menganalisis indeks keluarga sehat (IKS) di gampong lintasan hauling PT Mifa Bersaudara. Penelitian ini bersifat kuantitatif dengan menghitung indeks keluarga sehat dengan populasi seluruh KK yang ada didesa Peunaga Cut Ujong yang merupakan lintasan hauling PT Mifa Bersaudara. Teknik pengambilan sampel menggunakan total populasi yang berjumlah 286 KK. Penilaian IKS berdasarkan keluarga ber KB, ibu bersalin di faskes, bayi mendapat imunisasi lengkap, ASI eksklusif, balita mendapatkan pemantauan pertumbuhan, penderita TB Paru, penderita hipertensi, penderita gangguan jiwa, anggota keluarga tidak ada yang merokok, JKN, sarana air besrih, dan jamban sehat dan diukur indek keluarga sehat pada setiap gampong. Hasil penelitian diperoleh bahwa jumlah keluarga yang pra sehat $(54,90 \%)$ dan tidak sehat $(1,75 \%)$. Keluarga yang pra sehat sebagian besar penyebabnya adalah masih ada anggota keluarga yang merokok $(38,11 \%)$ yang berdampak pada menderita TB $(1,40 \%)$. Di Desa Peunaga Cut Ujong masih ada keluarga yang belum mempunyai jamban $(2,10 \%)$. Kesimpulan IKS di desa Peunaga Cut UJong berada pada indeks keluarga pra sehat, dalam peningkatan IKS perlu adanya sinergi dengan aparat gampong, Puskesmas Meureubo. Pemerintah Daerah dan Perusahaan PT Mifa Bersaudara dalam penetapan program di bidang kesehatan. Peningkatan IKS ini dapat dilakukan dengan pembentukan kader sehat digampong guna untuk memantau kesehatan masyarakat di desa Lintasan Hauling Peunaga Cut Ujong Kecamatan Meureubo Kabupaten Aceh Barat.
\end{abstract}

Kata Kunci: Indeks, Keluarga, Sehat

Riwayat Artikel

Diterima : 24 September 2019

Disetujui : 21 Oktober 2019

Dipublikasi : :31 Oktober 2019 


\title{
ANALYSIS OF A HEALTY FAMILY INDEX IN THE HAULING CROSSROADS OF PT. MIFA BERSAUDARA WEST ACEH
}

\begin{abstract}
The healthy Indonesia program is an effort to improve the quality of Indonesia's human life which is manifested in the 2015-2019 Ministry of Health strategic plan. PT Mifa Bersaudara is a sibling company that started operating in 2012. The purpose of this study was to analyze the Index of Healthy Families (IHF) in hauling PT Mifa Bersaudara. This research is quantitative by calculating the index of healthy families with a population of all families in the village Peunaga Cut Ujong which is the hauling trajectory of PT Mifa Bersaudara. The sampling technique uses a total population of 286 households. IHF assessment is based on family planning families, mothers giving birth in health facilities, babies receiving complete immunizations, exclusive breastfeeding, toddlers receiving growth monitoring, pulmonary TB sufferers, hypertension sufferers, people with mental disorders, no smoking family members, JKN, clean water facilities, and healthy latrines and measured by the healthy family index in each village. The results obtained that the number of families who are pre-healthy $(54.90 \%)$ and unhealthy $(1.75 \%)$. Most prehealthy families are still having family members who smoke $(38.11 \%)$ who have an impact on TB (1.40\%). In Peunaga Cut Ujong Village there are still families who do not have latrines $(2.10 \%)$. Conclusion IHF in Peunaga Cut UJong village is in the pre-healthy family index, in increasing IHF there needs to be synergy with village officials, the Meureubo Community Health Center. The Local Government and PT Mifa Bersaudara Company in the determination of programs in the health sector. This increase in IHF can be done by forming healthy cadres in the villages in order to monitor public health in the Hauling Peunaga Cut Ujong village of Meureubo District, West Aceh Regency.
\end{abstract}

Keywords: Index, Family, Healthy 


\section{PENDAHULUAN}

Program Indonesia sehat sebagai upaya meningkatkan kualitas hidup manusia Indonesia yang diwujudkan dalam rencana strategis kementrian kesehatan 2015-2019 dengan Sasaran meningkatnya derajat kesehatan dan status gizi masyarakat. Dalam mewujudkan masyarakat sehat perlu dilakukannya usaha-usaha preventif melalui upaya kesehatan dan pemberdayaan masyarakat yang dapat memandirikan masyarakat untuk hidup sehat. Pemahaman yang harus ditanamkan dalam masyarakat adalah pemahaman paradigm sehat, hak dalam mendapatkan pelayanan kesehatan dan memiliki jaminan kesehatan nasional. Strategi dititik beratkan pada upaya penguatan promoting dan preventif. ${ }^{(1)}$

Salah satu upaya promotif dan preventif yang dilakukan dengan penentuan indek keluarga sehat. Suatu keluarga dikatakan sehat jika anggota keluarga mampu mempertahankan keadaan kesehatan anggota keluarga agar tetap memiliki produktivitas yang tinggi dengan penilaian 12 indikator yang sudah

\section{METODE}

Penelitian ini bersifat penelitian kuantitatif dengan desain survey analitik yaitu mengukur indek keluarga sehat pada gampong Lintasan Hauling PT MIFA Bersaudara yaitu gampong peunaga Cut Ujung di Wilayah kerja puskesmas Meureubo. Tahapan penelitian yang dilakukan adalah sebagai berikut :

1 Rapat koordinasi dengan pihak puskesmas Meureubo yang merupakan puskesmas wilayah gampong lintasan hauling PT Mifa

2 Melakukan survey indikator keluarga yang meliputi : keluarga ber $\mathrm{KB}$, ibu bersalin di faskes, bayi mendapat imunisasi lengkap, ASI eksklusif, ditetapkan oleh Kementrian kesehatan yaitu : keluarga ber $\mathrm{KB}$, ibu bersalin di faskes, bayi mendapat imunisasi lengkap, ASI eksklusif, balita mendapatkan pe,antauan pertumbuhan, penderita TB Paru, penderita hipertensi, penderita gangguan jiwa, anggota keluarga tidak ada yang merokok, JKN, sarana air besrih, dan jamban sehat. Penentuan IKS berfungsi untuk mengukur jumlah keluarga sehat dan sebagai indikator dalam perencanaan di bidang kesehatan yang dapat meningkatkan derajat kesehatan masyarakat Indonesia. (2)

PT Mifa Bersaudara merupakan perusahaan batu bara yang mulai beroperasi pada tahun 2012 di Kabupaten Aceh Barat. Gampong Peunaga Cut Ujong merupakan salah satu Gampong lintasan Haulingnya PT Mifa yang sering mendapatkan keluhan dari masyarakat. Berdasarkan hal tersebut maka analisa ingin mengetahui indeks keluarga sehat di salah satu Gampong lintasan Haulingnya PT Mifa sebagai dasar penetapan program di bidang kesehatan dalam penggunaan dana CSR PT Mifa.

balita mendapatkan pemantauan pertumbuhan, penderita TB Paru, penderita hipertensi, penderita gangguan jiwa, anggota keluarga tidak ada yang merokok, JKN, sarana air besrih, dan jamban sehat dan diukur indek keluarga sehat pada setiap gampong.

3 Mengklasifikasi setiap keluarga yang sehat, pra sehat dan tidak sehat. Penentuan Indeks Keluarga sehat menggunakan formula sebagai berikut :

$\mathrm{IKS}=\frac{\text { jumlah indikator keluarga sehat }}{\text { jumlah } 12 \text { indikator yang tidak ada dalam keluarga }}$ 


\section{1) Nilai indeks $>0,800$ : keluarga sehat}

HASIL

Hasil penelitian yang dilakukan di Desa Peunaga Ujong, sebagaimana diketahui bahwa sebagian besar keluarga di gampong Peunaga Cut Ujong adalah keluarga pra sehat $(54,90 \%)$. Berdasarkan analisis data didapatkan hasil, bahwa status keluarga di desa Peunaga Cut Ujong paling banyak terdapat keluarga dengan status pra sehat yakni 157 keluarga (54,90\%), selanjutnya status keluarga tidak sehat sebanyak 124 keluarga (43,36\%), sedangkan status keluarga yang paling sedikit terdapat pada status keluarga sehat yakni 5 keluarga $(1,75 \%)$ [Tabel. 1].

Dari 286 keluarga dusun yang memiliki status keluarga tidak sehat terbanyak berada di dusun 2 dan 4 yakni berjumlah 2 keluarga. Sedangkan dusun dusun yang paling banyak status keluarga pra sehat terdapat di dusun 4 yakni sebanyak 84 keluarga, dan status keluarga sehat terbanyak di dusun 4 yakni sebanyak 68 keluarga [Tabel. 2].

Berdasarkan jumlah bayi, diketahui yang diberikan Asi Ekslusif sebanyak 22 orang $(84,62 \%)$ sedangkan bayi yang tidak diberikan Asi ekslusif sebanyak 4 orang $(15,38 \%)$ [Tabel. 1]. Bayi yang diberikan ASI Ekslusif terbanyak terdapat di dusun 2 yakni sebanyak 10 orang, dan bayi yang tidak diberikan ASI Eksklusif paling banyak terdapat di dusun 2 yakni sebanyak 2 orang [Tabel. 3 ].

Berdasarkan status merokok, diketahui di Desa Peunaga Cut Ujong, anggota keluarga yang merokok sebanyak 177 orang $(61,89 \%)$, sedangkan anggota keluarga yang tidak merokok sebanyak 109 orang $(38,11 \%)$ [Tabel. 1]. Anggota keluarga yang merokok paling banyak terdapat di dusun 4 sebanyak 99 keluarga $(35,71 \%)$ sedangkan untuk anggota keluarga yang
2) Nilai indeks $0,500-0,800:$ pra - sehat

3) Nilai indeks $<0,500$ : tidak sehat

tidak merokok terbanyak berada di dusun 4 sebanyak 55 keluarga $(44,44 \%)$ [Tabel. 4].

Berdasarkan angka kejadian TB, diketahui anggota keluarga yang menderita TB sebanyak 4 keluarga $(1,40 \%)$ sedangkan keluarga yang tidak menderita TB sebanyak 282 keluarga (98,60\%) [Tabel. 1]. Penderita TB terbanyak terdapat di dusun 2 yakni sebanyak 2 keluarga, sedangkan dusun yang paling banyak keluarga yang tidak menderita TB terdapat di dusun 4 yakni sebanyak 153 keluarga [Tabel. 5].

Berdasarkan status berobat penderita TB diketahui, penderita yang berobat berjumlah sebanyak 3 orang $(0,75 \%)$ sedangkan penderita TB yang tidak berobat sebanyak 1 orang $(0,25 \%)$ [Tabel. 1]. Penderita TB di dusun 1,2, dan 4 yang masing-masing 1 orang berobat secara teratur, sedangkan penderita TB di dusun 2 sebanyak 1 orang tidak berobat [Tabel. 6].

Berdasarkan ketersediaan sarana dan prasarana, diketahui keluarga yang memiliki sarana air bersih yakni sebanyak 279 orang $(97,55 \%)$, sedangkan keluarga yang tidak memiliki sarana air bersih yakni sebanyak 7 orang $(2,45 \%)$ [Tabel. 1]. Keluarga yang memiliki sarana air bersih terbanyak terdapat di dusun 4 yakni sebanyak 152 keluarga, sedangkan keluarga yang tidak memiliki sarana air bersih terbanyak berada di dusun 1 yakni 3 keluarga $(5,17 \%)$ [Tabel. 7].

Berdasarkan ketersediaan jamban, diketahui bahwa keluarga yang memiliki yang jamban sebanyak 280 keluarga $(97,90 \%)$, sedangkan keluarga yang tidak memiliki jamban sebanyak 6 keluarga $(2,10 \%)$ [Tabel. 1]. Keluarga yang memiliki jamban terbanyak berada di dusun 4 yakni sebanyak 150 keluarga dan keluarga yang tidak memiliki 
jamban terbanyak berada di Dusun 4 yakni sebanyak 4 keluarga [Tabel. 8]

\section{PEMBAHASAN}

Hasil kajian indeks keluarga sehat di lintasan hauling PT MIFA Bersaudara yaitu Gampong Peunaga Cut Ujong dengan jumlah 286 kepala keluarga, sebagian besar adalah keluarga pra sehat $(54,90 \%)$. Dusun 2 dan 4 memiliki masing-masing 2 keluarga dengan status keluarga tidak sehat. Keluarga yang tidak sehat tidak memenuhi 12 indikator yang sudah ditetapkan. Indikator yang tidak terpenuhi yaitu tidak mengikuti program $\mathrm{KB}$, ada anggota keluarga yang merokok, tidak mengikuti JKN, dan menderita TB. Hasil wawancara dengan kepala keluarga dengan status keluarga tidak sehat, alasan tidak mengikuti KB karena faktor agama dan culture yang masih berpegang teguh bahwa KB tidak diperbolehkan dalam agama. Temuan lainnya adalah tidak mengikuti JKN karena masih melakukan pengobatan secara tradisional yang dianggap masih sangat ampuh ketika anggota keluarga sakit.

Pencapaian ASI Ekslusif di Gampong Peunaga Cut Ujong sudah baik, sebagian besar mendapatkan ASI Eksklusif (84,6\%). Manfaat pemberian ASI Eksklusif sebagai nutrisi meningkatkan daya tahan tubuh, meningkatkan kecerdasan, meningkatkan jalinan kasih sayang. Hasil wawancara pada keluarga yang tidak memberikan ASI Eksklusif sebagian besar menyatakan tidak mengetahui pentingnya ASI Eksklusif dan kurangnya dukungan dari anggota keluarga lainnya seperti suami, ibu dan mertua karena faktor budaya. Hasil penelitian Isroni menunjukan bahwa faktor dominan yang mempengaruhi ibu untuk memberikan ASI Eksklusif adalah pendidikan, pekerjaan, sikap, peran petugas, keterpaparan media dan peran suami. $^{(3)}$

Perilaku merokok masih sangat tinggi hal ini berdampak pada meningkatnya ISPA dan TB pada anggota keluarga. Persentase keluarga merokok mencapai $61,89 \%$ yang hamper semua dusun anggota keluarga. Rokok berisiko untuk terjadinya beberapa jenis penyakit, baik lokal maupun sistemik. Banyak bahan kimia yang terkandung dalam rokok diantaranya Tar, nikotin, dan karbonmonoksida berbahaya dalam asap rokok. Hasil penelitian Sri widati menunjukan bahwa pesan rokok yang ada pada bungkusan tidak menghambat masyarakat untuk tidak merokok. ${ }^{(4)}$

Tingginya yang masih mengkonsumsi rokok maka berdampak pada TB. Penderita TB di Peunaga Cut Ujong berjumlah 4 penderita $(1,4 \%)$ yang merupakan perokok berat dan juga sebagian anggota keluarga menderita ISPA. Rokok juga menyebabkan radang gusi, penyakit periodontal, karies akar, alveolar bone loss, tooth loss, serta berhubungan dengan munculnya lesi-lesi khas pada jaringan lunak rongga mulut ${ }^{(5)}$

Sebagian besar keluarga Peunaga Cut Ujong memiliki sarana air bersih. Sarana air bersih didapatkan dri sumur BOR dan PDAM. Akan tetapi, air bersih yang mereka konsumsi sering juga mendapatkan kendala baik secara kualitas maupun kuantitas. Air bersih merupakan sumber kehidupan untuk keperluan sehari-hari dan diminum setelah dimasak terlebih dahulu. Air dikatakan bersih ketika bebas dari kualitas fisik, kimia, biologi dan radiologi ${ }^{(6)}$

Gampong Peunaga Cut Ujong masih ada keluarga yang tidak memiliki jamban $(2,10 \%)$, padahal gampong ini terletak dipinggiran kota yang dekat dengan kota kabupaten. Perilaku hidup bersih dan sehat masih kurang sehingga berdampak pada penyakit diare yang 
tinggi setiap tahunnya. Ketidakpemilikan jamban sangat berpangruh terhadap timbulnya penyakit lingkungan seperti diare. Sarana jamban merupakan kebutuhan primer setiap manusia untuk mencegah timbulnya berbagai penyakit. ${ }^{(7)}$ Hasil penelitian

\section{KESIMPULAN DAN SARAN}

Sebagian besar keluarga di Peunaga Cut Ujong berada pada status keluarga pra sehat $(54,90 \%)$. 4 keluarga dengan status keluarga tidak sehat karena tidak memenuhi 12 indikator yang sudah ditetapkan. Indikator yang tidak terpenuhi yaitu tidak mengikuti program KB, ada anggota keluarga yang merokok, tidak mengikuti JKN, dan menderita TB. Untuk peningkatan IKS di desa Peunaga Cut UJong perlu adanya

\section{DAFTAR PUSTAKA}

1. Tjandrarini DH, Dharmayanti I, Upaya P, Masyarakat K. Pencapaian Indonesia Sehat Melalui Pendekatan Indeks Achieving Healthy Indonesia through Public Health Development Index. 2018;90-6.

2. Tahun KB, Fauzan A, Chotimah I, Hidana R. Implementasi Program Indonesia Sehat Dengan Pendekatan Keluarga ( PIS-PK ) Di Puskesmas Mulyaharja Pendahuluan Metode Penelitian. 2019;2(3).

3. Astuti I. Determinan Pemberian ASI Eksklusif Pada Ibu Menyusui. :60-8.

4. Widati S. Efektivitas Pesan Bahaya Rokok Pada Bungkus Rokok Terhadap Perilaku Merokok Masyarakat Miskin. J Promosi Kesehatan dan Pendidik Kesehatan.
Erlina menunjukkan bahwa penggunaan jamban dipengaruhi oleh pendidikan, pengetahuan, sikap, kepemilikan jamban, sarana air bersih, pembinaan petugas puskesmas dan dukungan aparat desa, kader Posyandu \& LSM. ${ }^{(8)}$

sinergi antara apparat gampong, Puskesmas Meureubo. Pemerintah Daerah dan Perusahaan PT Mifa Bersaudara dalam penetapan program di bidang kesehatan. Peningkatan IKS ini dapat dilakukan dengan pembentukan kader sehat di gampong guna untuk memantau kesehatan masyarakat di desa Lintasan Hauling Peunaga Cut Ujong Kecamatan Meureubo Kabupaten Aceh Barat.

2013;1(2):105-10.

5. Putri ARK. Pengaruh Merokok Terhadap Kesehatan Gigi Dan Rongga Mulut.

6. Agustina DV. Analisa Kinerja Sistem Distribusi Air Bersih PDAM Kecamatan Banyumanik di Perumnas Banyumanik ( Studi Kasus Perumnas Banyumanik Kel. Srondol Wetan ). Anal Kinerja Sist Distrib Air Bersih PDAM Kec Banyuwangi di Perumnas Banyumanik. 2007;2:13.

7. Darsana IN, Mahayana IMB, Patra IM. Faktor-faktor yang Berhubunga dengan Kepemilikan Jamban Keluarga Di Desa Jehem Kecamatan Tembuku Kabupaten Bangli tahu 2012. Kesehatan. 2012;4(2):124-33.

8. Pane E. Pengaruh Perilaku Keluarga terhadap. 2008;17550(1):229-34. 


\section{LAMPIRAN}

Tabel [1]. Distribusi Frekuensi Variabel Berdasarkan Indikator Keluarga Sehat Di Desa Peunaga Cut Ujong.

\begin{tabular}{llcc}
\hline \multicolumn{1}{c}{ Variabel } & Kategori & Frekuensi & \% \\
\cline { 2 - 4 } Status Keluarga & Sehat & 124 & 43,36 \\
\cline { 2 - 4 } & Pra Sehat & 157 & 54,90 \\
\cline { 2 - 4 } & Tidak Sehat & 5 & 1,75 \\
\hline \multirow{2}{*}{ ASI Eksklusif } & Total & $\mathbf{2 8 6}$ & $\mathbf{1 0 0}$ \\
& Ya & 22 & 84,62 \\
\cline { 2 - 4 } & Tidak & 4 & 15,38 \\
\hline \multirow{2}{*}{ Status Merokok } & Total & $\mathbf{2 6}$ & $\mathbf{1 0 0}$ \\
& Ya & 109 & 38,11 \\
\cline { 2 - 4 } & Tidak & 177 & 61,89 \\
\hline \multirow{2}{*}{ Penderita TB } & Total & $\mathbf{2 8 6}$ & 1,40 \\
\hline & Ya & 4 & 98,60 \\
\cline { 2 - 4 } & Tidak & 282 & $\mathbf{1 0 0}$ \\
\hline Penderita TB & Total & $\mathbf{2 8 6}$ & 0,75 \\
Berobat & Ta & 3 & 0,25 \\
\hline \multirow{2}{*}{$\begin{array}{l}\text { Kepemilikan } \\
\text { Sarana Air Bersih }\end{array}$} & Total & Ya & $\mathbf{1 0 0}$ \\
\hline & Tidak & $\mathbf{4}$ & 97,55 \\
\hline Kepemilikan & Total & $\mathbf{2 8 6}$ & 2,45 \\
\hline Jamban & Ya & 280 & $\mathbf{1 0 0}$ \\
\hline & Tidak & $\mathbf{2 8 6}$ & $\mathbf{1 0 0}$ \\
\hline & Total & & \\
\hline
\end{tabular}

Tabel 2. Distribusi Frekuensi Status Keluarga Berdasarkan Indikator Keluarga Sehat Per Dusun Di Desa Peunaga Cut Ujong

\begin{tabular}{ccccccccc}
\hline \multirow{2}{*}{ Dusun } & \multicolumn{2}{c}{ Tidak Sehat } & \multicolumn{2}{c}{ Pra Sehat } & \multicolumn{2}{c}{ Sehat } & \multirow{2}{*}{ Total } & \multirow{2}{*}{ \% } \\
\cline { 2 - 6 } & $\mathbf{F}$ & $\mathbf{\%}$ & $\mathbf{F}$ & $\mathbf{\%}$ & $\mathbf{F}$ & $\mathbf{\%}$ & & \\
\hline 1 & 1 & 1,72 & 27 & 46,55 & 30 & 51,72 & 58 & 100 \\
\hline 2 & 2 & 3,57 & 35 & 62,50 & 19 & 33,93 & 56 & 100 \\
\hline 3 & 0 & 0,00 & 11 & 61,11 & 7 & 38,89 & 18 & 100 \\
\hline 4 & 2 & 1,30 & 84 & 54,55 & 68 & 44,16 & 154 & 100 \\
\hline Total & $\mathbf{5}$ & $\mathbf{1 , 7 5}$ & $\mathbf{1 5 7}$ & $\mathbf{5 4 , 9 0}$ & $\mathbf{1 2 4}$ & $\mathbf{4 3 , 3 6}$ & $\mathbf{2 8 6}$ & $\mathbf{1 0 0}$ \\
\hline
\end{tabular}


Tabel [4]. Distribusi Frekuensi Bayi diberikanAsi Ekslusif Per Dusun Di Desa Peunaga Cut Ujong

\begin{tabular}{|c|c|c|c|c|c|}
\hline \multirow{2}{*}{ Dusun } & \multicolumn{4}{|c|}{ Asi Eksklusif } & \multirow{2}{*}{ Total } \\
\hline & $\mathbf{Y a}$ & $\%$ & Tidak & $\%$ & \\
\hline 1 & 6 & 85,71 & 1 & 14,29 & 7 \\
\hline 2 & 10 & 83,33 & 2 & 16,67 & 12 \\
\hline 3 & 0 & 0 & 0 & 0,00 & 0 \\
\hline 4 & 6 & 85,71 & 1 & 14,29 & 7 \\
\hline Total & 22 & 84,62 & 4 & 15,38 & 26 \\
\hline
\end{tabular}

Tabel [6]. Distribusi Frekuensi Terdapat Anggota Keluarga Tidak ada yang Merokok per DusunDi Desa Peunaga Cut Ujong

\begin{tabular}{|c|c|c|c|c|c|}
\hline \multirow[b]{2}{*}{ Dusun } & \multicolumn{4}{|c|}{ Merokok } & \multirow[b]{2}{*}{ Total } \\
\hline & Ya & $\%$ & Tidak & $\%$ & \\
\hline 1 & 26 & 44,83 & 32 & 55,17 & 58 \\
\hline 2 & 20 & 35,71 & 36 & 64,29 & 56 \\
\hline 3 & 8 & 44,44 & 10 & 55,56 & 18 \\
\hline 4 & 55 & 35,71 & 99 & 64,29 & 154 \\
\hline Total & 109 & 38,11 & 177 & 61,89 & 286 \\
\hline
\end{tabular}

Tabel [7]. Distribusi Frekuensi penderita TB per Dusun Di Desa Peunaga Cut Ujong

\begin{tabular}{|c|c|c|c|c|c|}
\hline \multirow{2}{*}{ Dusun } & \multicolumn{4}{|c|}{ Penderita TB } & \multirow[b]{2}{*}{ Total } \\
\hline & Ya & $\%$ & Tidak & $\%$ & \\
\hline 1 & 1 & 1,72 & 57 & 98,28 & 58 \\
\hline 2 & 2 & 3,57 & 54 & 96,43 & 56 \\
\hline 3 & 0 & 0,00 & 18 & 100 & 18 \\
\hline 4 & 1 & 0,65 & 153 & 99,35 & 154 \\
\hline Total & 4 & 1,40 & 282 & 98,60 & 286 \\
\hline
\end{tabular}

Tabel [8]. Distribusi Frekuensi penderita TB yang Berobat Di Desa Peunaga Cut Ujong

\begin{tabular}{|c|c|c|c|c|c|}
\hline \multirow[b]{2}{*}{ Dusun } & \multicolumn{4}{|c|}{ TB BEROBAT } & \multirow[b]{2}{*}{ Total } \\
\hline & Ya & $\%$ & Tidak & $\%$ & \\
\hline 1 & 1 & 100 & 0 & 0 & 1 \\
\hline 2 & 1 & 50 & 1 & 50 & 2 \\
\hline 3 & 0 & 0 & 0 & 0 & 0 \\
\hline 4 & 1 & 100 & 0 & 0 & 1 \\
\hline Total & 3 & 0,75 & 1 & 0,25 & 4 \\
\hline
\end{tabular}


Tabel [9]. Distribusi Frekuensi Rumah Yang Memiliki Sarana Air Bersih Di Desa Peunaga Cut Ujong

\begin{tabular}{cccccc}
\hline \multirow{2}{*}{ Dusun } & \multicolumn{3}{c}{ Memiliki Sarana Air Bersih } & \multirow{2}{*}{ Total } \\
\cline { 2 - 5 } & Ya & $\mathbf{\%}$ & Tidak & \% & \\
\hline 1 & 55 & 94,83 & 3 & 5,17 & 58 \\
\hline 2 & 55 & 98,21 & 1 & 1,79 & 56 \\
\hline 3 & 17 & 94,44 & 1 & 6 & 18 \\
\hline 4 & 152 & 98,70 & 2 & 1,30 & 154 \\
\hline Total & 279 & 97,55 & 7 & 2,45 & 286 \\
\hline
\end{tabular}

Tabel [10]. Distribusi Frekuensi Kepemilikan Jamban Per Dusun Di Desa Peunaga Cut Ujong

\begin{tabular}{|c|c|c|c|c|c|}
\hline \multirow{2}{*}{ Dusun } & \multicolumn{4}{|c|}{ Memiliki Jamban } & \multirow{2}{*}{ Total } \\
\hline & Ya & $\%$ & Tidak & $\%$ & \\
\hline 1 & 58 & 100,0 & 0 & 0,00 & 58 \\
\hline 2 & 55 & 98,21 & 1 & 1,79 & 56 \\
\hline 3 & 17 & 94,44 & 1 & 6 & 18 \\
\hline 4 & 150 & 97,40 & 4 & 2,60 & 154 \\
\hline Total & 280 & 97,90 & 6 & 2,10 & 286 \\
\hline
\end{tabular}

Tabel Nama dan Keterangan Keluarga Yang Tidak Sehat

\begin{tabular}{|c|c|c|c|}
\hline Nama & Dusun & IKS & Keterangan \\
\hline Keluarga A & 4 & 0,400 & $\begin{array}{l}\text { Tidak mengikuti program KB, ada anggota } \\
\text { keluarga yang merokok, tidak mengikuti JKN, } \\
\text { dan menderita TB. }\end{array}$ \\
\hline Keluarga B & 4 & 0,400 & $\begin{array}{l}\text { Tidak mengikuti program KB, ada anggota } \\
\text { keluarga yang merokok, tidak mengikuti JKN, } \\
\text { dan menderita TB. }\end{array}$ \\
\hline Keluarga C & 2 & 0,333 & $\begin{array}{l}\text { Tidak mengikuti program KB, ada anggota } \\
\text { keluarga yang hipertensi tidak berobat secara } \\
\text { teratur, tidak memiliki sumber air bersih, ada } \\
\text { anggota keluarga merokok dan menderita TB. }\end{array}$ \\
\hline Keluarga D & 2 & 0,333 & $\begin{array}{l}\text { Tidak mengikuti program KB, balita tidak } \\
\text { dipantau pertumbuhannya, ada anggota } \\
\text { keluarga yang merokok, tidak mengikuti JKN } \\
\text { dan menderita TB. }\end{array}$ \\
\hline Keluarga E & 1 & 0,400 & $\begin{array}{l}\text { Tidak memiliki sumber air bersih, ada anggota } \\
\text { keluarga merokok, ada anggota keluarga yang } \\
\text { hipertensi tidak berobat secara teratur dan } \\
\text { menderita TB }\end{array}$ \\
\hline
\end{tabular}


Tabel Nama dan Keterangan Keluarga Yang Menderita TB

\begin{tabular}{cccccc}
\hline $\begin{array}{c}\text { Nama } \\
\text { Kepala } \\
\text { Keluarga }\end{array}$ & Dusun & IKS & $\begin{array}{c}\text { Status } \\
\text { IKS }\end{array}$ & $\begin{array}{c}\text { Status } \\
\text { Berobat }\end{array}$ & $\begin{array}{c}\text { Terdapat } \\
\text { Anggota } \\
\text { Keluarga } \\
\text { Merokok }\end{array}$ \\
\hline Keluarga A & 1 & 0,800 & $\begin{array}{c}\text { Tidak } \\
\text { Sehat }\end{array}$ & Berobat & Tidak Ada \\
\hline Keluarga B & 2 & 0,714 & $\begin{array}{c}\text { Tidak } \\
\text { Sehat }\end{array}$ & $\begin{array}{c}\text { Tidak } \\
\text { Berobat }\end{array}$ & Tidak Ada \\
\hline Keluarga C & 2 & 0,571 & $\begin{array}{c}\text { Tidak } \\
\text { Sehat }\end{array}$ & Berobat & Ada \\
\hline Keluarga D & 4 & 0,857 & $\begin{array}{c}\text { Tidak } \\
\text { Sehat }\end{array}$ & Berobat & Ada \\
\hline
\end{tabular}

